\title{
DYNAMIC INVESTIGATION OF A SUSPENSION FOOTBRIDGE
}

J M W Brownjohn ${ }^{1}$, A A Dumanoglu ${ }^{2}$, C A Taylor ${ }^{3}$,

${ }^{1}$ Lecturer, Nanyang Technological University, Nanyang Avenue, Singapore 2263

${ }^{2}$ Professor, Karadeniz Technical University, Trabzon, Turkey,

${ }^{3}$ Reader, University of Bristol, Bristol BS8 1TR, UK

\section{ABSTRACT}

This paper describes the analytical and experimental investigation of a $50 \mathrm{~m}$ span pedestrian suspension footbridge in Central Wales, UK. In the analytical study modelling of the three dimensional structure determined vibration modes involving deck, towers and cables. The prototype testing employed hammer (impact) testing and excitation by pedestrians to determine the corresponding measured modes. The testing showed that adequate descriptions of vibration characteristic of flexible structures can be obtained without artificial forcing but that appropriate instrumentation should be used. The validated analysis showed that the concrete panelling in the bridge and other structural details have a significant effect on stiffness and the testing demonstrated the susceptibility of this lightly damped structure to pedestrian induced vibration. 


\section{INTRODUCTION}

The Dolerw ('w' pronounced as 'ue') suspension footbridge in Central Wales was tested and analysed in 1985 by a team from the University of Bristol, UK as part of a program of research in integrity monitoring of structures in the UK. The investigation was also intended to obtain specific information for this type of structure as a pre-amble to a research studies on the dynamic behaviour of European long span bridges $^{1-3}$, primarily aimed at predicting their response to earthquakes.

For rigid structures such as buildings, dams and short span bridges forced vibration testing (FVT) ${ }^{\mathbf{4 - 6}}$ techniques have been an effective tool for monitoring their integrity. Long span suspension bridges are relatively flexible and FVTs are not usually effective due to the difficulty of providing adequate dynamic forces at the very low fundamental frequencies $(<1 \mathrm{~Hz})$ of these structures. Other sources of excitation, including transient and ambient loads then have to be considered as alternatives.

Because of its flexibility and small size Dolerw bridge was found to be easily excited by hammer impact. In hammer or impact testing ${ }^{7}$ the force input can be measured and a transfer function with phase information can be established which is more desirable for modal analysis than the response power spectra available from ambient vibration surveys (AVSs) ${ }^{8}$, which provide only amplitude information. Hammer testing, with backup AVS was chosen for this bridge.

To calibrate the suspension bridge modelling techniques being developed, the first 30 theoretical modes of vibration of the bridge were calculated using a three dimensional analysis. This analysis gave modes of vibration involving translation and rotation in vertical, lateral and longitudinal axes. The prototype testing aimed to check the predicted frequencies and mode shapes.

The work on this bridge is relevant today because of the fashion for using short span cable-stayed and suspension bridges for pedestrian access when aesthetics rank in importance together with economics. Such bridges are often 'lively'; Dolerw bridge in particular was known to be susceptible to excitation by pedestrians, to the extent that a hanger connection had to be replaced on one occasion as a result of large amplitude oscillations, probably due to vandalism.

\section{BRIDGE STRUCTURAL DETAILS}

The Dolerw bridge ${ }^{9}$, Fig. 1, provides access to Dolerw Park in Newtown, Mid Wales, across the upper reaches of the River Severn.

The suspended deck is $50 \mathrm{~m}$ long (Fig. 2). There are no side spans and the unequal cable back stays are straight with anchorages $16.5 \mathrm{~m}$ from the east tower and $18.5 \mathrm{~m}$ from the west tower. 
The deck provides a footway $1.85 \mathrm{~m}$ wide. Longitudinal bending strength is provided by two BS4360 grade 50C rolled steel hollow section box chords $200 \mathrm{~mm}$ x $300 \mathrm{~mm}$ (height), $12.5 \mathrm{~mm}$ thickness (other steel sections are $10 \mathrm{~mm}$ thick). The floor of the bridge consists of prestressed precast concrete panels $1.85 \mathrm{~m}$ long, $400 \mathrm{~mm}$ wide and $50 \mathrm{~mm}$ deep supported on longitudinal $\mathrm{L}$ section beams welded to the longitudinal chords (Fig. 1a). This is topped with a $30 \mathrm{~mm}$ layer of reinforced concrete, a waterproofing membrane and hand laid mastic asphalt surfacing $20 \mathrm{~mm}$ thick. Longitudinal chords are connected by a plan bracing system of $80 \mathrm{~mm}$ x $80 \mathrm{~mm}$ steel angles to provide lateral stability. At every $5 \mathrm{~m}$ there are also $100 \mathrm{~mm} \times 100 \mathrm{~mm}$ crossbeams forming rigid connections between the longitudinal beams (just visible with the plan bracing under the deck in Fig. 1).

The deck is fixed in position at the east end and is free to move under expansion and live loading at the other. Fixed end bearings are of pin-type, while free end bearings comprise pinned steel swing links.

The towers comprise twin welded boxes, $8.75 \mathrm{~m}$ high and $300 \mathrm{~mm}$ by $300 \mathrm{~m}$ section, with a single transverse bracing box member $2.5 \mathrm{~m}$ from the top and knuckle bearings at the base to allow free rotation about the upstream/downstream direction axis. At the tower top curved machined blocks form the saddles where friction forces are sufficient to prevent cable slippage.

The deck is connected to the cables by hangers at $5 \mathrm{~m}$ intervals where crossbeams are also located. Hangers are $27 \mathrm{~mm}$ diameter steel rod, screwed at each end and pinned and clamped to the cable using high strength friction grip bolts. Each main cable consists of a $35 \mathrm{~mm}$ diameter galvanised locked coil wire rope with a sag of $6.25 \mathrm{~m}$.

\section{MATHEMATICAL MODELLING}

In the finite element modelling, the complete bridge is considered in terms of a number of discrete elements represented by appropriate stiffness and mass matrices.

Deck longitudinal chords and crossbeams, tower pylons and crossbeams, cables and hangers are all represented by beam elements with 6 degrees of freedom (DOF). Of these elements deck chords and crossbeams and tower crossbeams have only linear elastic stiffness properties, others also include geometric stiffness properties due to axial loads. Fig. 3 shows the finite element mesh (and measurement points for the experimental study).

The $\mathrm{H}$ form of the tower is represented by five beam elements. There is no longitudinal cantilever action in the towers since the legs are hinged at the base; the frame resists torsion and lateral sway. 
Each segment of cable between hangers, and each hanger itself is represented by a single beam element.

The joints between the $\mathrm{L}$ section diagonal bracings and the longitudinal deck beams are only welded on half of the L section, creating some uncertainty for the fixity. In the model the bracing was represented by 3 DOF space truss elements with hinges rather than rigid joints.

To model the combined effect of the concrete deck panels together with their continuous topping and asphalt asphalt surface is not straightforward, and the prototype test subsequently established that there is significant composite action between the slabs and beams. The panels as such contribute to the overall mass (approximately $38 \%$ of deck mass) but not to the stiffness of the deck. However, by casting a uniform and continuous coating of concrete on these panels an $80 \mathrm{~mm}$ deep concrete panel is created. The concrete may have different stiffness properties along the bridge span and transverse to it, and may be non-linear because while the topping is continuous, gaps exist between the panels themselves. To eliminate some uncertainties a parametric study was done considering the concrete panels and concrete top as contributing varying mass and stiffness to the structure. Analyses with no stiffness contribution from the concrete panels produced frequencies of lateral modes of vibration very much smaller than the experimental results, clearly showing that the need to incorporate fully the stiffness contribution of the panels. For the analysis described here the panels were modelled as plate elements $80 \mathrm{~mm}$ deep, $2.5 \mathrm{~m}$ wide and $2.1 \mathrm{~m}$ long with $6 \mathrm{DOF}$ at each nodal point, sharing nodal points with (and hence coplanar with) the longitudinal chords.

The railings, bolted to the chords, are continuous along the deck and past the tower and would be expected to provide additional stiffness. Their contribution to mass is included but without modelling at a level of detail inappropriate to this study the exact contribution to stiffness is uncertain.

\section{FREE VIBRATION ANALYSIS}

For geometrically non-linear structures such as suspension bridges the equations of equilibrium are formulated for the deformed configuration of the structure. If the deflections over the given load range are small the only effect to be considered will be the change in the stiffness due to initial (dead load) forces in the structure and a linear analysis around this state gives acceptable accuracy.

The dead load horizontal cable tension $\mathrm{T}$ is estimated by assuming the bridge to be a pair of catenaries each with load $\rho$ per unit horizontal length $(\mathrm{x})$, for which the profile (y) of the (stretched) cable is given by 


$$
\mathrm{T} \frac{\mathrm{d}^{2} \mathrm{y}}{\mathrm{dx} \mathrm{x}^{2}}=\rho .
$$

The solution of Eq. 1 is a parabola (origin $\mathrm{x}, \mathrm{y}=0$ at midspan):

$$
\mathrm{y}=\rho \mathrm{x}^{2} / 2 \mathrm{~T}
$$

For a cable with sag $\mathrm{s}$ and span $\mathrm{L}_{\mathrm{t}}$, the horizontal component of axial tension, $\mathrm{T}_{\mathrm{o}}$, is:

$$
\mathrm{T}_{\mathrm{o}}=\frac{\rho \mathrm{L}_{\mathrm{t}}^{2}}{8 \mathrm{~s}} .
$$

The load $\rho$ is determined from the total deck and cable mass shared by the two cables and the deck is assumed to be simply and uniformly supported, even in its slightly cambered configuration. The tower loads follow from the geometry, and the deck weight is shared among the hangers. The dead load forces in these components and towers are accounted for using a geometric stiffness matrix ${ }^{\mathbf{1 0}}$ which is associated with the conventional stiffness matrix. For a $3 \mathrm{DOF} /$ node beam element length $\mathrm{L}$, area A, modulus $\mathrm{E}$, axial tension $\mathrm{T}$ and flexural inertia I the total stiffness matrix used to relate nodal loads $\mathbf{f}$ to nodal displacements $\mathbf{u}$ in local coordinates is

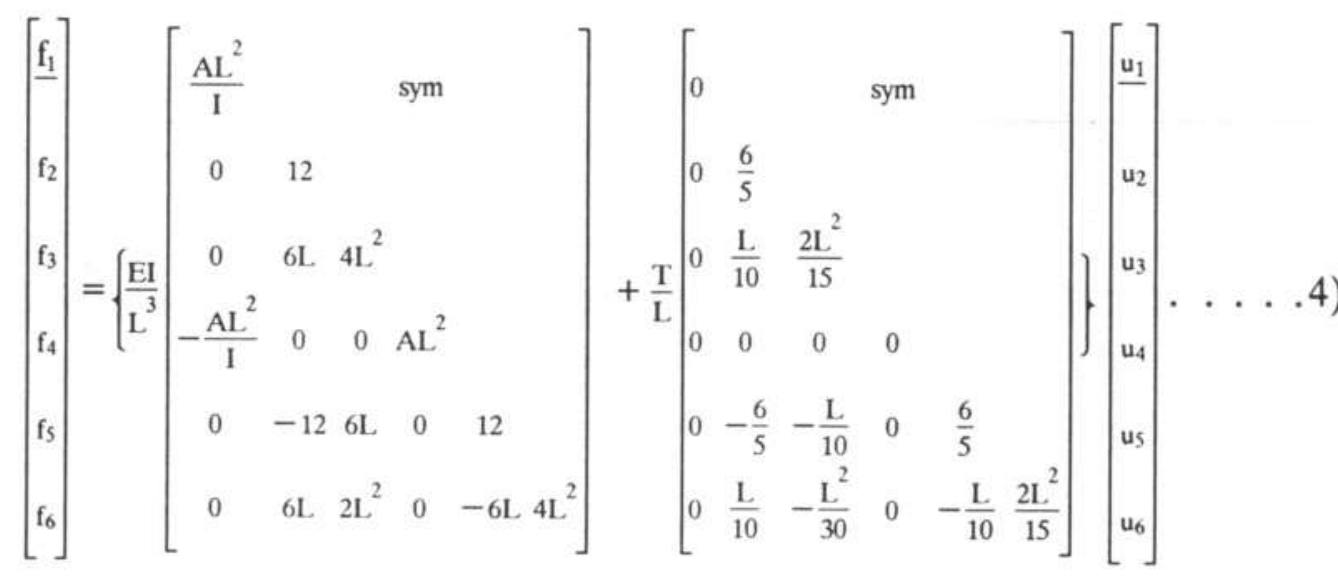

If the axial force is compressive $\mathrm{T}$ will be replaced by (-T). Eq. 4 may be written as

$$
\mathbf{f}=\left\{\mathbf{k}_{\mathrm{e}}+\mathbf{k}_{\mathrm{g}}\right\} \mathbf{u}
$$

where $\mathbf{k}_{\mathrm{e}}$ is the conventional elemental stiffness matrix and $\mathbf{k}_{\mathbf{g}}$ is the elemental geometric stiffness matrix. Eq. 4 can be expanded to include $6 \mathrm{DOF} /$ node beam elements by assuming that bending in orthogonal planes are independent. The global stiffness matrices $\mathbf{K}_{\mathrm{e}}$ and $\mathbf{K}_{\mathrm{g}}$ are assembled from the elemental $\mathbf{k}_{\mathrm{e}}$ and $\mathbf{k}_{\mathrm{g}}$ transformed to global coordinates.

Having defined the elastic and geometric stiffness matrices the equation of free vibration of a suspension bridge structure, considered as a multi-degree of freedom system, can be formulated as

$$
\mathbf{M} \ddot{\mathbf{u}}+\mathbf{K u}=0
$$

where $\mathbf{M}$ is the lumped mass matrix, $\mathbf{u}$ is the nodal displacements vector (now in global coordinates). $\mathbf{K}$ is the total stiffness matrix $\mathbf{K}=\mathbf{K}_{\mathbf{e}}+\mathbf{K}_{\mathbf{g}}$. 
For free vibration at a fixed frequency $\omega$ rads/second, the oscillations are a harmonic function of time $(t)$ and the deflection vector $\mathbf{u}(t)$ can be written as

$$
\mathbf{u}(\mathrm{t})=\mathrm{xe}^{\mathrm{i} \omega \mathrm{t}}
$$

in which $\mathbf{x}$ is the time invariant vector of nodal amplitudes and $i=\sqrt{-}$ I. From eqs. 6 and 7 a generalised eigenvalue problem is obtained as

$$
\mathbf{K} \mathbf{x}=\lambda \mathbf{M x}
$$

in which $\lambda=\omega^{2}$. If the system has $n$ degrees of freedom the solution of Eq.8 will yield n eigenvalues $\lambda_{i} ; i=1 \rightarrow n$ that represent the squares of the natural frequencies $\omega_{\mathrm{i}}{ }^{2}$, and $n$ eigenvectors $\mathbf{x}_{\mathbf{i}}$ which are the corresponding modes of vibration.

The SAPIV finite element code ${ }^{11}$ was adapted to include the geometric stiffness. To represent the bridge 103 beam elements, 20 thin plate elements and 20 truss elements were employed giving a total of 406 DOF. The analysis was run for the lowest 30 modes using the determinant search method.

\section{THEORETICAL MODES OF VIBRATION}

The first 30 modes of vibration are summarised in Table 1 and representative modes are plotted in Fig. 4 which show plan, sheared elevation or both.

In the elevations solid lines indicate the mode shapes, and broken lines in the elevations the original undeformed shape of the bridge. In the plan views chain dotted lines show cable deformations. The lateral displacements are scaled to zero in the elevation views to avoid confusion, and hangers are not shown.

It is usual to identify sequences in the mode shapes, e.g. in the symmetry and number of nodal points, for example there is usually a sequence of torsional modes where the deck rotates about a spanwise axis. The lowest of these (designated T1) is symmetric about the deck midpoint and has 0 (stationary) nodal points, the next highest (T2) is anti-symmetric about the deck midpoint, with 1 nodal point, then $\mathrm{T} 3$ is symmetric with 2 nodes etc.. The modes are classified according to the strongest component of the motion, e.g. $\mathrm{V}$ is a mode in which deck and cable move in (mainly) the vertical plane, $\mathrm{L}$ is (mainly) lateral, CL is (mainly) lateral motion of the cables and To is lateral motion of the towers, with participation of the cables. The distinction between types of mode is not always clear, e.g. between CL and To modes.

Vibrations in modes 1-3 are all in the vertical plane with negligible lateral displacement components, so these are modes V1-V3. For suspension bridges the symmetry of the fundamental mode (0-node symmetric vs. 1-node anti-symmetric) depends on several factors of the deck fixity, hanger and cable configuration. Here the first anti-symmetric mode is out of sequence, appearing as the fundamental vertical mode $\mathrm{V} 1$, at $0.885 \mathrm{~Hz}$. 
Mode 4 is an unusual coupled (pendular) mode between (predominant) lateral and vertical motion. This is taken as the fundamental lateral mode $\mathrm{L} 1$, although there is an element of torsion. Note that the motions of the deck and both cables are all in phase.

Modes 5-7 and 9 are symmetric and anti-symmetric cable modes (CL). There is a sequence of pairs of cable modes with the 0-1-2-3 etc. node sequence of alternating symmetry. The lower frequency mode of each power has vibration of the cables in phase with each other, with some lateral deflection of the towers, the higher (stiffer) mode is antiphase with minimal tower deflection.

Like mode 3, mode 10 is again a coupled mode between vertical and lateral motion, but because the motions of the deck and cables are in antiphase in the horizontal plane this induces torsional vibration of the deck. This mode is described as the lowest torsional mode (T1) but could be interpreted as the second lateral mode (L2).

Modes 11 and 12, are tower modes To1 and To2 that do not fit into the above cable mode sequence and involve significant tower vibrations, coupled by the cables.

Mode 13 is also a coupled mode with vertical and lateral motions. The mode shape is similar to a classical first antisymmetric torsional beam mode, but there is still a considerable amount of lateral motion of the deck beams. Higher order modes of this type $(17,23,28)$ extend the transition from predominantly lateral to predominantly torsional vibration. 


\begin{tabular}{|c|c|c|c|c|}
\hline Mode & identifier & $\mathrm{f}_{\mathrm{th}} / \mathrm{Hz}$ & nodes & type/symmetry \\
\hline 1 & V1 & 0.885 & 1 & $\mathrm{~V}-\mathrm{A}$ \\
\hline 2 & V2 & 1.226 & 0 & V-S \\
\hline 3 & V3 & 1.874 & 2 & V-S \\
\hline 4 & L1 & 2.220 & 0 & L-S \\
\hline 5 & CL1 & 2.477 & 0 & CL-S \\
\hline 6 & CL2 & 2.529 & 0 & CL-S* \\
\hline 7 & CL3 & 2.963 & 1 & CL-A \\
\hline 8 & V4 & 3.094 & 3 & V-A \\
\hline 9 & CL4 & 3.192 & 1 & CL-A* \\
\hline 10 & $\mathrm{~T} 1$ & 3.239 & 0 & T-S \\
\hline 11 & To1 & 3.375 & 0 & To-S \\
\hline 12 & To2 & 3.593 & 0 & To-A \\
\hline 13 & $\mathrm{~T} 2$ & 3.856 & 1 & $\mathrm{~T}-\mathrm{A}$ \\
\hline 14 & CL5 & 4.144 & 2 & $\mathrm{CL}-\mathrm{S}^{*}$ \\
\hline 15 & CL6 & 4.510 & 2 & CL-S \\
\hline 16 & V5 & 4.759 & 4 & V-S \\
\hline 17 & T3 & 5.409 & 2 & T-S \\
\hline 18 & CL7 & 5.533 & 3 & CL-A* \\
\hline 19 & CL8 & 5.586 & 3 & CL-A* \\
\hline 20 & CL9 & 6.629 & 4 & CL-S* \\
\hline 21 & CL10 & 6.656 & 4 & CL-S* \\
\hline 22 & V6 & 6.780 & 5 & V-A \\
\hline 23 & $\mathrm{~T} 4$ & 7.204 & 3 & $\mathrm{~T}-\mathrm{A}$ \\
\hline 24 & CL11 & 7.598 & 5 & CL-A* \\
\hline 25 & CL12 & 7.616 & 5 & CL-A* \\
\hline 26 & CL13 & 8.445 & 6 & CL-S* \\
\hline 27 & CL14 & 8.453 & 6 & CL-S \\
\hline 28 & T5 & 9.144 & 4 & T-S \\
\hline 29 & V7 & 9.172 & 6 & V-S \\
\hline 30 & CL15 & 9.204 & 7 & CL-A* \\
\hline
\end{tabular}

$\mathrm{V}=$ vertical $\mathrm{L}=$ lateral; $\mathrm{T}=$ torsion; $\mathrm{CL}=$ cable, lateral $; \mathrm{To}=$ tower $\mathrm{S}=$ symmetric, $\mathrm{A}=$ antisymmetric; ${ }^{*}=$ cable motions in antiphase

\section{PROTOTYPE TESTING}

\section{Test procedure}

The intention was to check the theoretical modes by measuring frequencies, damping values and mode shapes for at least 2 vertical, 2 lateral, 1 torsional and 1 cable modes. The end points of the deck cross beams, corresponding to nodal points in the analytical model, were chosen as locations (stations) for measurement, as shown in Fig. 3.

\section{Equipment}

A single servo-accelerometer (type: Schaevitz LSOC) with an operating range of $\pm 0.25 \mathrm{~g}$ referred to as ACA and three piezoelectric accelerometers (type: $1 \mathrm{x}$ Endevco 7751, 2x Endevco 224C) referred to as ACB, ACC and ACD respectively were used. ACA and ACB were high resolution accelerometers capable of measuring down to less than $0.0001 \mathrm{~g}$ and $0.1 \mathrm{~Hz}$. 
The primary means of forcing vibration of the bridge was a 13 pound sledgehammer instrumented with a force crystal. As a secondary means of excitation ambient excitation from pedestrians was to be used.

Signals were recorded on a four channel FM tape recorder (type: Racal Store-4DS) and converted to the frequency domain by a two channel signal processor (type: Solartron 1200). As small a frequency step as possible is desirable for more accurate definition of the resonances which appear as peaks in the frequency spectrum, so the range $0.2 \mathrm{~Hz}-10.2 \mathrm{~Hz}$ was used, giving $0.02 \mathrm{~Hz}$ resolution.

\section{Ambient excitation}

This objective of the first part of the testing was to provide initial estimates of the likely natural frequencies of the bridge in vertical, torsional and lateral vibration. To do this the signals from a pair of accelerometers were recorded for 30 minutes during which time the bridge was open to pedestrians (providing most of the force input).

With ACA and ACB placed on opposite sides of the deck, slightly offset from the midspan position ( $1 \mathrm{~g}$ and $2 \mathrm{~g}$ ) the signals were analysed by the Solartron for 30 minutes, to average out noise over 36 records. Fig. 5 shows the frequency spectrum from ACA and the phase angle between ACA and ACB. The linearly decreasing phase shift $\left(21^{\circ} / \mathrm{Hz}\right)$ is due to a high order low pass filter in ACA which delays the signal by $58 \mathrm{~ms}$, while ACB has no significant delay. Torsional modes with the accelerometer positions moving in antiphase show up where the phase is offset $180^{\circ}$ from the filtering slope. Fig.5 suggests a set of possible vertical modes at approximately $1.2 \mathrm{~Hz}, 2.0 \mathrm{~Hz}, 3.3 \mathrm{~Hz}$ $4.9 \mathrm{~Hz}$ and $6.8 \mathrm{~Hz}\left(0^{\circ}\right.$ offset $)$ and a set of possible torsional modes at $1.7 \mathrm{~Hz}, 3.5 \mathrm{~Hz}$, $4.8 \mathrm{~Hz}$ and $7.4 \mathrm{~Hz}\left(180^{\circ}\right.$ offset $)$.

One 30 minute ambient recording was made with ACA and ACB aligned horizontally at $2 \mathrm{f}$ and $2 \mathrm{~d}$ respectively to identify lateral modes. Fig. 6 shows auto power spectra from ACA (midspan), with a dominant peak at about $1.7 \mathrm{~Hz}$.

\section{Hammer testing}

Whereas the ambient testing was used to obtain some information about the likely frequencies of interest and some discrimination between vertical and torsional modes, the full modal survey relied on measurements of the transient response.

The hammer testing was conducted as follows. The two sensitive accelerometers (ACA and ACB) were located at two of the positions indicated in Fig. 3. Pedestrians were prevented from using the bridge while three successive hammer blows were applied to the deck at one minute intervals. The intervals were used to allow a record length of at least the $\mathrm{T}=50$ seconds required to give the $0.02 \mathrm{~Hz}(=1 / \mathrm{T})$ frequency

spacing. Analysis of a single transient in a pair of input and response signals can 
produce a clear transfer function while 'double hits' destroy the clarity of the analysis and should be avoided.

The vertical modes of the bridge were obtained by placing ACA at position $1 \mathrm{~g}$ and $\mathrm{ACB}$ at each of the remaining 8 positions on side 1 and were excited by hitting the deck (asphalt surface) in the middle of the path. Torsional modes were measured with the same accelerometer positions but excited by hitting along the deck vertically on the opposite side to the accelerometers. Lateral modes were measured by turning the accelerometers on their sides to measure horizontally and excited by leaning over the railing and hitting the longitudinal chord horizontally.

To excite symmetric modes only, the deck was hit at midspan (f) and to excite antisymmetric modes more strongly the deck was hit at the one-third position (h).

The above procedure allowed the ratio of modal amplitudes (mode shapes) for each mode to be determined either by comparing ratios of response of ACA and ACB or be comparing ratios of response of $\mathrm{ACB}$ and the hammer signal.

Fig. 7 shows the amplitude of the transfer function measured between vertical acceleration response at $2 \mathrm{~b}$ and hammer force signal (at $2 \mathrm{f}$ ), showing resonant peaks. The strong peak excited at approximately $1 \mathrm{~Hz}$ corresponds to the lowest vertical mode which has weak ambient response (Fig. 5) and this shows one advantage of using artificial excitation.

Due to instrumentation problems, limited data was obtained for the main cable vibration, indicating modes at $6.16 \mathrm{~Hz}, 6.24 \mathrm{~Hz}, 6.44 \mathrm{~Hz}, 8.4 \mathrm{~Hz}$ and $9.94 \mathrm{~Hz}$ in addition to $1 \mathrm{~L}, 1 \mathrm{~T}, 2 \mathrm{~T}$ and $3 \mathrm{~T}$ (but not 2L).

\section{Data analysis}

The transfer function is normally defined as the (complex) ratio of system output to system input. In the case of the hammer testing input is force, the system is the bridge, and output is acceleration. This type of transfer function can be analysed by standard modal analysis procedures ${ }^{12}$ to provide a set of natural frequencies, damping ratios and mode shapes. Some good quality transfer function data was analysed to determine frequencies and damping ratios.

As a check on these values, approximate values of frequency and damping ratio were obtained using half-power bandwidths (HPB) of ambient excitation response, although such data are known to less reliable, particularly for damping ratios which can be overestimated significantly.

To determine mode shapes required good quality acceleration/force data for each position and for a number of reasons this was not always available. The mode shapes were therefore obtained by using the transfer function computation in the Solartron 
to compute the complex ratios between the signals of the two accelerometers measuring the response to the hammer. The moduli of these ratio gave the modal amplitudes relative to the accelerometer chosen as the reference in each of the recordings, with the phase close to $0^{\circ}$ or $180^{\circ}$. Satisfactory mode shapes were obtained in this way for most of the modes.

\section{COMPARISON OF MODAL DATA WITH THEORETICAL VALUES}

Table 2 summarises experimental and theoretical frequencies ( $f_{\exp }$ and $\mathrm{f}_{\mathrm{th}}$ ) for modes detected. Except where indicated* the data were obtained by the curve fitting technique.

Table 2 Comparison of measured and theoretical modes

$\begin{array}{clllll}\text { mode identifier nodes } & \text { type/symmetry } & \mathrm{f}_{\mathrm{th}} / \mathrm{Hz} & \mathrm{f}_{\exp } / \mathrm{Hz} & \text { damping }(\%) \\ \text { V1 } & 1 & \text { V-A } & 0.885 & 1.053 & 2.68 \\ \text { V2 } & 0 & \text { V-S } & 1.226 & 1.227 & 0.50 \\ \text { V3 } & 2 & \text { V-S } & 1.874 & 2.127 & 0.84 \\ \text { V4 } & 3 & \text { V-A } & 3.094 & 3.330 & 0.27 \\ \text { V5 } & 4 & \text { V-S } & 4.759 & 4.910 & 0.28 \\ \text { V6 } & 5 & \text { V-A } & 8.780 & 6.850 & 0.29 \\ & & & & & \\ \text { L1 } & 0 & \text { L-S } & 2.220 & 1.690 & 1.00 \\ \text { L2 } & 1 & \text { L-A } & - & 6.980 & 0.70 \\ & & & & & \\ \text { T1 } & 0 & \text { T-S } & 3.239 & 3.560^{\circ} & 0.84^{\circ} \\ \text { T2 } & 1 & \text { T-A } & 3.865 & 4.780 . & 0.50 \\ \text { T3 } & 2 & \text { T-S } & 5.409 & 7.340^{\circ} & -\end{array}$

" indicates data obtained from auto power HPB

The measured mode shapes for the above modes are plotted in Fig. 8. The circles represent measured data points, the solid lines represent the appropriate theoretical modes and the broken lines the configuration of the undeformed deck.

The first six vertical modes were easily established from the measurements but identification of torsional and lateral modes was harder because significant response was obtained in both vertical and horizontal directions for modes at $1.69 \mathrm{~Hz}, 3.56 \mathrm{~Hz}$, $4.78 \mathrm{~Hz}, 6.98 \mathrm{~Hz}$ and $7.34 \mathrm{~Hz}$, consistent with the observations on the analytical modes lateral and torsional modes (Table 1).

The mode shapes for T2 and T3 are not clear, in particular T2 is confused with V5 which occurs at a close frequency. To determine these mode shapes accurately would require a total of four accelerometers, using the difference of signals obtained from the same spanwise position at opposite sides of the footway.

From the strength of the peak in Fig. $6,1.66 \mathrm{~Hz}$ is a judged to be lateral, and from the mode shapes, $1.66 \mathrm{~Hz}$ and $3.56 \mathrm{~Hz}$ must be the first (symmetric) lateral and torsional modes L1 and T1 respectively, and modes at $4.78 \mathrm{~Hz}$ and $7.34 \mathrm{~Hz}$ the second and third torsional $(2 \mathrm{~T}, 3 \mathrm{~T})$. 
The mode at $6.98 \mathrm{~Hz}$ is clear and strong in Fig. 6 and from Fig. 5 it has no torsion. The acceleration at this frequency vanishes at midspan so it is antisymmetric and was judged to be the second lateral mode (L2) although no corresponding second lateral mode was predicted by the modelling.

While the mode shapes are as expected, the agreement between measured and predicted natural frequencies could be better, the model underestimating the measured values, usually by less than $10 \%$. Clearly the modelling is not sufficiently detailed and some possible sources of error are suggested.

a) The longitudinal chords are restrained by a hinge at one end and a sliding bearing at the other, but in practice the bearings may be partially seized increasing the stiffness. Likewise in the hangers the idealized hinges at each end will not be realised in practice.

b) The axes of the various elements have been idealised for simplicity. For example the hangers connections are offset from the longitudinal chord axes and the concrete panels span between the chords not between the chord axes. Also the various beams and panels of the deck have neutral axes lying in different horizontal planes.

c) The contribution of the asphalt surfacing is taken as mass only, whereas it will contribute (slightly) to the stiffness. The value and distribution of the concrete mass is not certain.

d) The Value of Young's modulus for the concrete is uncertain.

e) The stiffening effect of the railings has not been included.

Adjusting the mass density of the concrete in the model is simple, and is the most significant of the above factors for vertical modes. By using slightly lower values, agreement of predicted and measured frequencies was obtained for all but V1.

The low theoretical values for torsional modes are probably due in the main to the taking the concrete panel width as $2.1 \mathrm{~m}$ and using a lumped mass matrix which concentrates concrete mass either side of the path, both factors increasing the polar moment of inertia.

Probably the high estimate of mode L1 frequency is due to the extra stiffness of panelling $2.1 \mathrm{~m}$ wide instead of $1.85 \mathrm{~m}$.

For relatively small bridges these details assume much more importance than they do in the modelling of much larger suspension bridges where the principal functions of the deck in the vertical plane are to contribute mass and to distribute traffic loads to the hangers, offering little vertical stiffness. In addition the deck has to be torsionally stiff (due to aeroelastic considerations ${ }^{\mathbf{1 3}}$ ) and needs to be sufficiently stiff laterally to resist static wind loads. 


\section{DISCUSSION}

The results from the testing are adequate to characterise the bridge despite the occasional poor data quality, due to problems with instrumentation. in particular the amplifiers and cabling used with piezoelectric accelerometers were subject to signal overload and drift. In subsequent tests servo type accelerometers and specially designed amplifiers based on the unit used with ACA have been used successfully.

Hammer testing, which is capable of providing, via the transfer function modulus, information about the participating dynamic mass and stiffness of a structure, is clearly applicable to a structure such as the Dolerw bridge, provided that a sufficiently powerful transient can be applied. Other potentially viable techniques which work best for some vertical modes include that used by Selberg ${ }^{14}$ who 'let some young men jump with the same frequency as the natural frequency for the type of oscillation under investigation' and 'step relaxation ${ }^{\mathbf{1 5}}$, where a static load is applied and the structure released from the deformed state. In both cases free decay oscillations are measured, from which damping can be determined accurately. The values of damping obtained for Dolerw are in line with values obtained from conventional steel and composite bridges of similar $\operatorname{span}^{16}$, although due to its flexibility the natural frequencies are lower.

As the ambient response measurements showed, forces due to walking or running can be significant. The force time history for a footfall load is approximately periodic with a period between 0.33 and 0.66 seconds but the waveform is not sinusoidal and there are strong harmonics of the fundamental, so that even structures with natural frequencies above $5 \mathrm{~Hz}$ can be strongly excited by walking or running. Wyatt ${ }^{17}$ has shown that a dynamic force of over $1.3 \mathrm{kN}$ at $2 \mathrm{~Hz}$ can be induced by a $75 \mathrm{~kg}$ jumper. Using the measured damping values and the validated model in a forced response analysis, a $1.3 \mathrm{kN}$ amplitude harmonic force at midspan would excite mode $3 \mathrm{~V}$ to an amplitude of approximately $1.65 \mathrm{~cm}$ at midspan, equivalent to $0.23 \mathrm{~g}$. With very low structural damping in light long span flexible structures such as Dolerw (and more usually now floor beams,) significant accelerations can be generated. Even though such levels of vibration are unlikely to be damaging to the structure they can cause concern to other users ${ }^{18}$, whose levels of tolerance are one or two orders of magnitude less than the structure's. 


\section{CONCLUSIONS}

Three principal conclusions from the work are:

1) For accurate modelling of relatively small suspension bridges such as this considerable structural detail may need to be included.

2) This is a good example of a light, long span structure which is flexible and has low damping. This, together with the coincidence of the structures main natural frequencies and the range of frequencies for maximum load from footfalls, makes it susceptible to vibrations induced by pedestrians. This is good for testing but undesirable for other users (and in extreme cases structural integrity).

3) Appropriate instrumentation must be used for testing this type of structure or the quality of data will be compromised.

\section{ACKNOWLEDGEMENTS}

The authors are grateful to Montgomery County Council for giving permission for and assistance with the prototype testing and to other staff of University of Bristol for their assistance. The project was supported by the Science and Engineering Research Council.

\section{REFERENCES}

1 Brownjohn, J. M. W., Dumanoglu, A. A., Severn, R. T. and Taylor, C. A. (1987) Ambient vibration measurements of the Humber Suspension Bridge and comparison with calculated characteristics, Proc. ICE, Pt. 2, Vol. 83 561-600.

2 Brownjohn, J. M. W., Dumanoglu, A. A., Severn, R. T. and Blakeborough, A. (1989) Ambient vibration survey of the Bosporus Suspension Bridge, Earthquake Engineering and Structural Dynamics Vol. 18, 263-283.

3 Brownjohn, J. M. W., Dumanoglu, A. A. and Severn, R. T. (1992) Ambient vibration survey of the Fatih Mehmet (Second Bosporus) Suspension Bridge, Earthquake Engineering and Structural Dynamics Vol. 21, 907-924.

4 Ohlsson, S. V. (1987) Dynamic characteristics of cable-stayed bridges -nonlinearities and weakly coupled modes of vibration, International Conference on Cable-stayed Bridges, Bangkok, 18-20 Nov. 421-431.

5 Varney, R. F. and Viner, J. G. (1971) Vibration studies relating to the failure of the Point Pleasant bridge, Public Roads Vol. 36 No. 8, June, 161-166.

6 Leonard, D. R. (1974) Dynamic tests on highway bridges -test procedures and equipment, Report TRRL LR 654, Transport and Road Research Laboratory, Crowthorne. 
7 Corelli, D. and Brown, D. L. (1984) Impact testing considerations, Proceedings, Second International Modal analysis Conference (IMACII), Orlando, Florida, 735-742.

8 Maclamore, V. R., Hart, G. C. and Stubbs, I. R. (1971) Ambient vibration response of two suspension bridges, ASCE Journal of Structural Division Vol. 97, Oct., 2567-2582.

9 Hayward, A. C. G. (1975) Suspension bridge at Newtown (Wales). Acier, Stahl, Steel No. 1, 13-19.

10 Przemienieckz, J. S. (1968) Theory of matrix structural analysis, McGraw Hill.

11 Bathe, K. G., Wilson, E. L., and Petersen, F. E. (1973) SAPIV A structural analysis program for static and dynamic response of linear systems, University of California, Earthquake Engineering Research Centre, Report No. EERC 73-11.

12 Ewins, D. J. (1984) Modal testing: theory and practice, Research Studies Press.

13 University of Washington (1954) Aerodynamic stability of suspension bridges with special reference to the Tacoma Narrows bridge, Bulletin no. 116, University of Washington Engineering Experiment Station, Seattle, Washington.

14 Selberg, A. (1950) Dampening effect in suspension bridges, IABSE Publications Vol. 10, 183-.

15 Douglas, B. M. and Reid, W. H. (1982) Dynamic tests and system identification of bridges, ASCE Journal of Structural Divsion Vol. 108, Oct, 2295-2312.

16 Eyre, R. and Tilly, G. P. (1977) Damping measurements on steel and composite bridges, Symposium on Dynamic Behaviour of Bridges, Report TRRL SR 275, Transport and Road Research Laboratory, Crowthorne, 22-39.

17 Wyatt, T. A. (1985) Floor excitation by rhythmic vertical jumping, Engineering Structures Vol. 7, July, 208-210.

18 Blanchard, J., Davies, B. L. and Smith, J. W. (1977) Design criteria and analysis for dynamic loading of footbridges, Symposium on Dynamic Behaviour of Bridges, Report TRRL SR 275, Transport and Road Research Laboratory, Crowthorne, 90-106. 

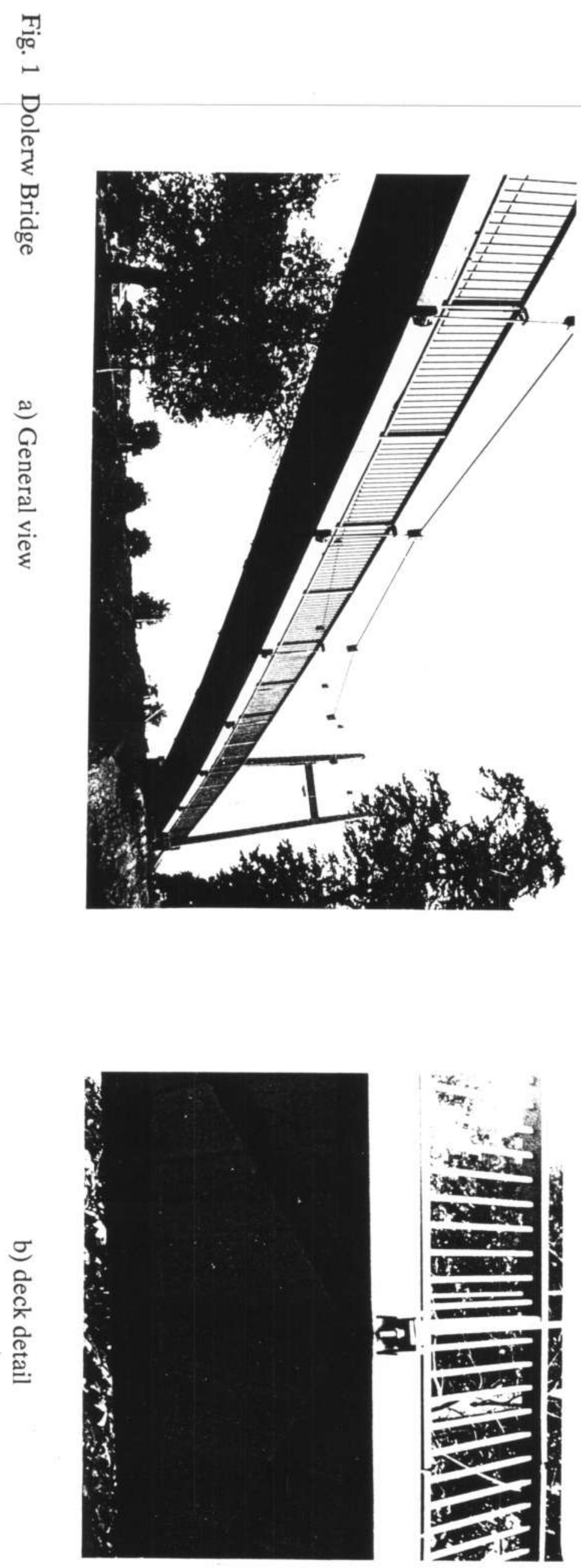


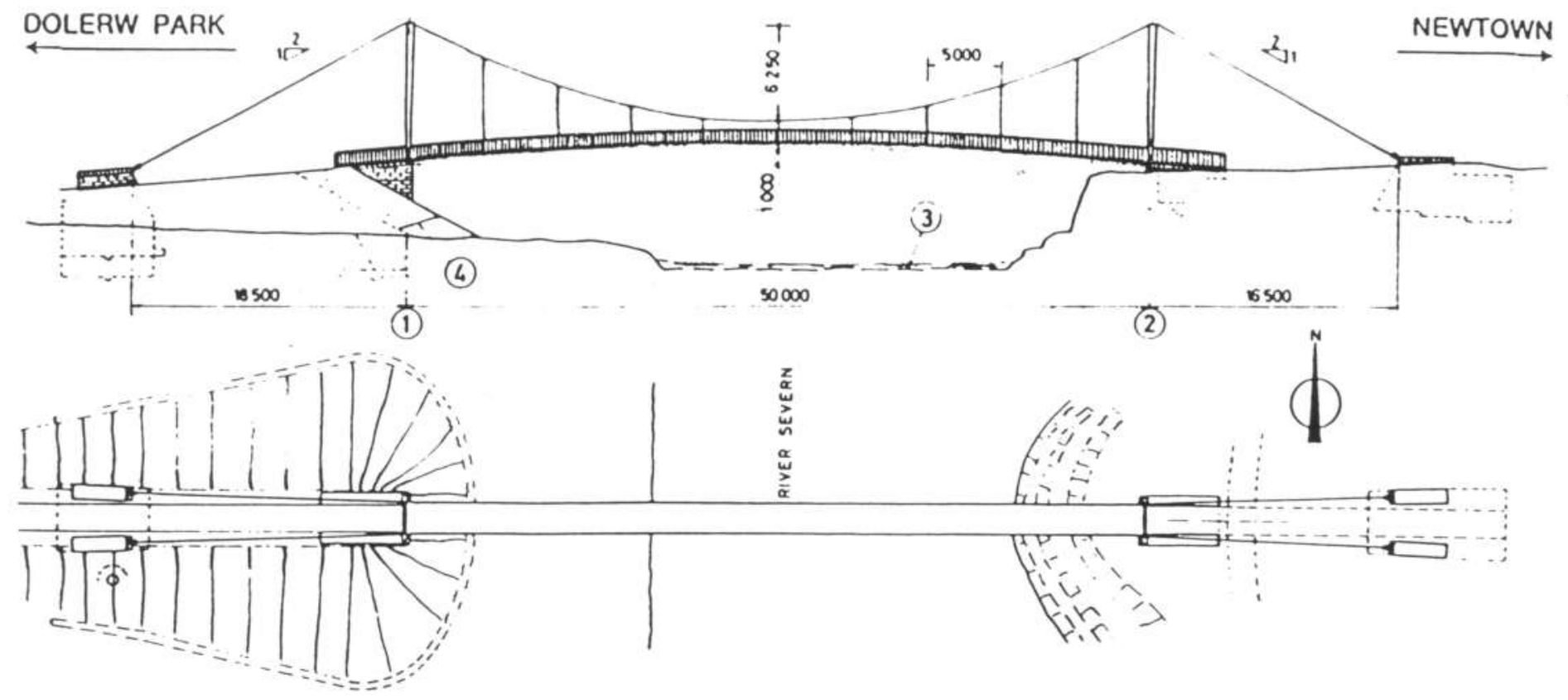

a) Elevation and plan

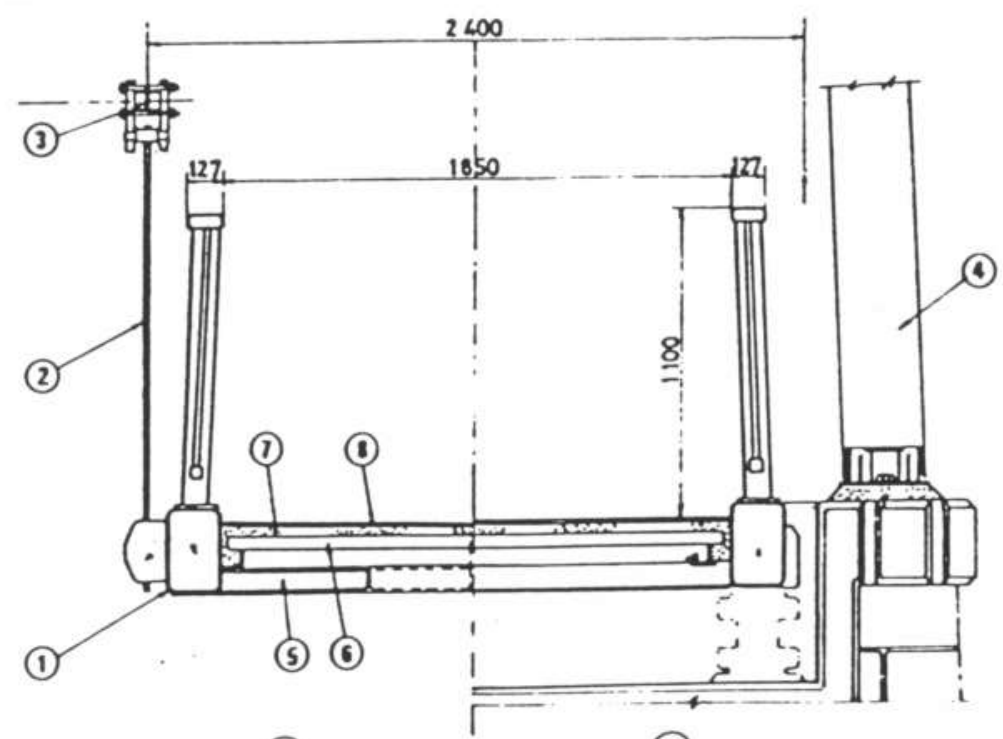

(A)

(B)
1) Longitudinal chord
2) Hanger
3) Main cable
4) Tower leg
5) Diagonal cross-bracing
6) Precast prestressed concrete panels
7) Reinforced concrete topping
8) Mastic asphalt surfacing on waterprof membrane
b) Cross sections ${ }^{9}$ A) at mid span B) at tower

Fig. 2 Dolerw Bridge structural details 


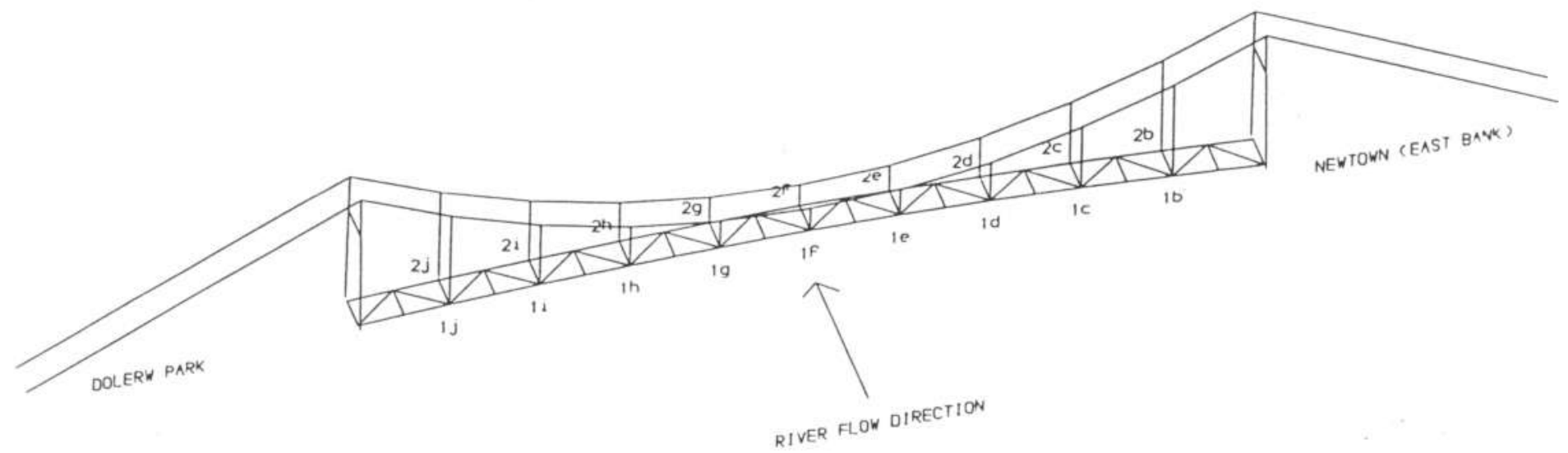

Fig. 3 Finite element mesh for mathematical modelling, showing measurement positions 


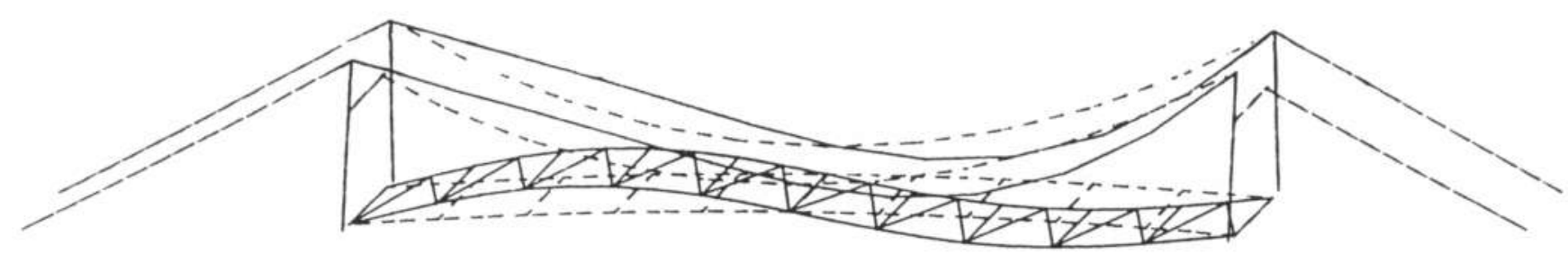

Mode 1 (1 node V-Asym) :

Frequency $0.885 \mathrm{~Hz}$ identifier:

V1

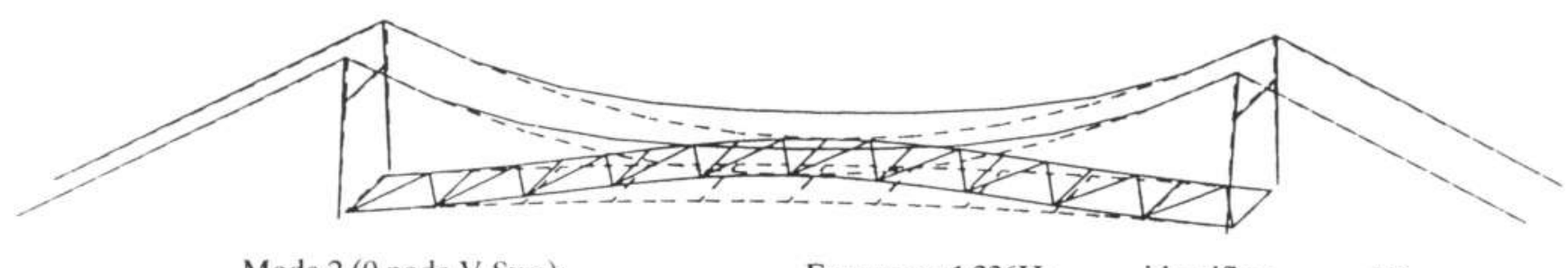

Mode 2 ( 0 node V-Sym):

Frequency $1.226 \mathrm{~Hz}$ identifier:

V2

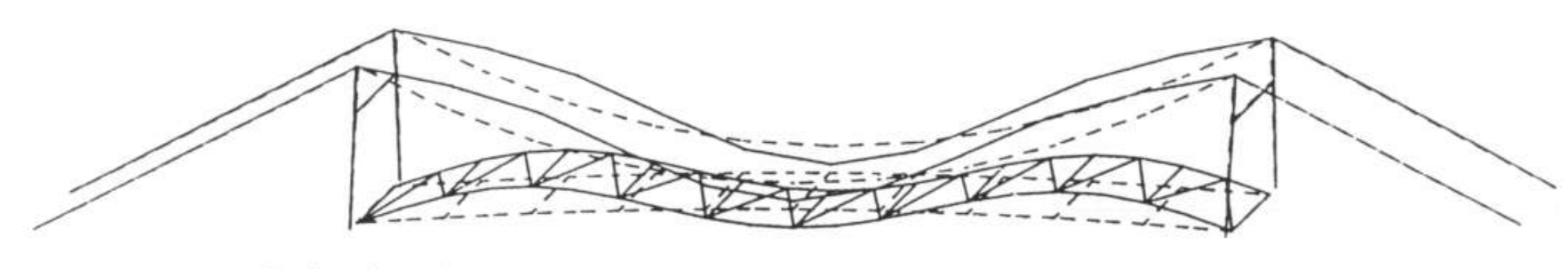

Mode 3 (2 node V-Sym):

Frequency $1.874 \mathrm{~Hz}$ identifier:

V3
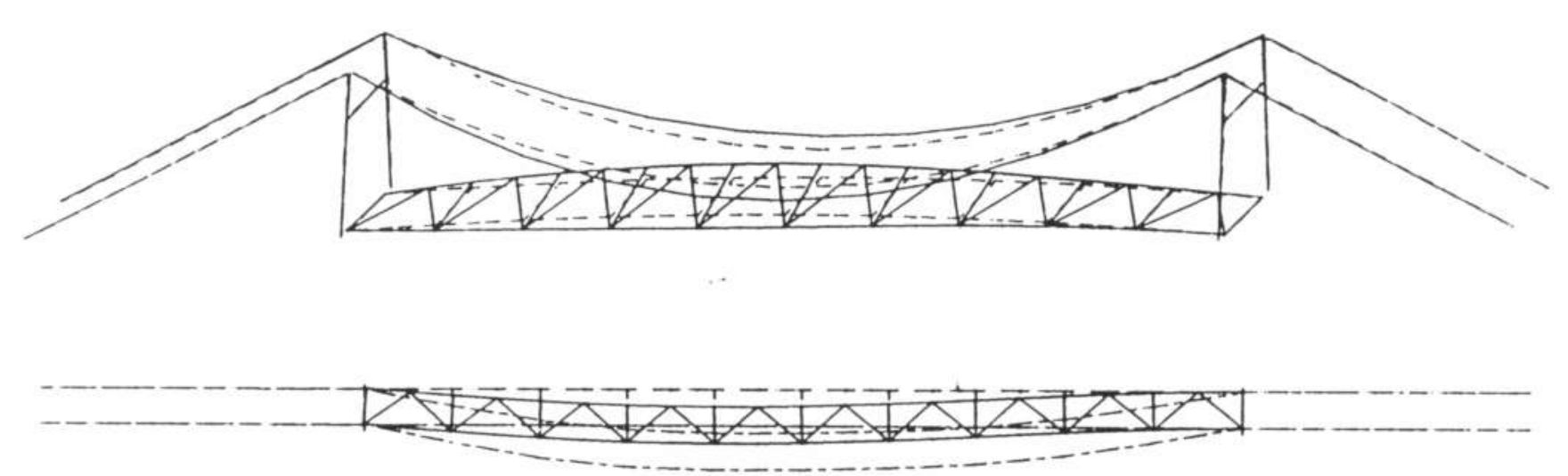

Mode 4 ( 0 node L-Sym):

Frequency $2.220 \mathrm{~Hz}$ identifier:

L1

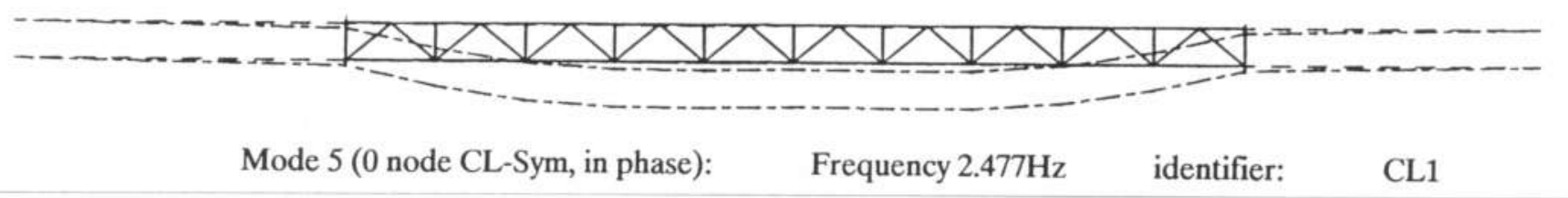

Fig. 4 (page 1 of 2) Theoretical modes 


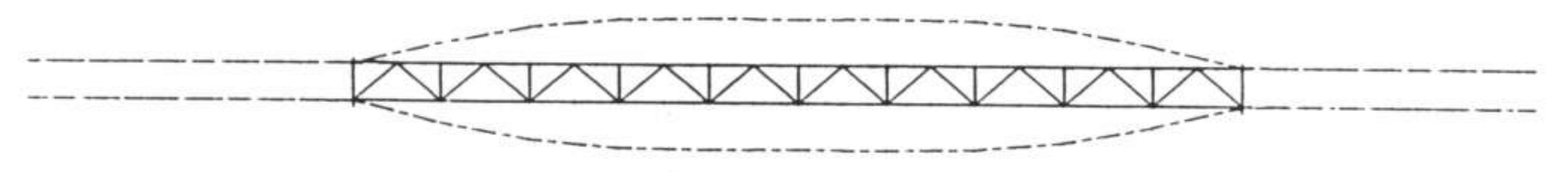

Mode 6 (0 node CL-Sym, out of phase): Frequency $2.529 \mathrm{~Hz} \quad$ identifier:

CL2
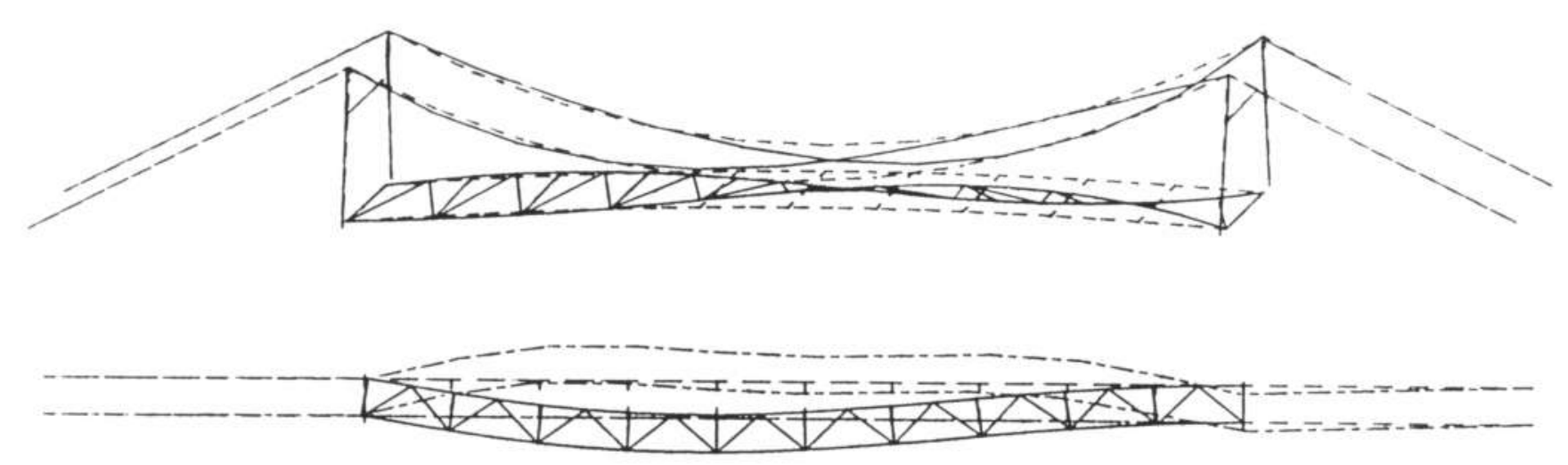

Mode 10 ( 0 node $\mathrm{T}$ sym):

Frequency $3.239 \mathrm{~Hz}$ identifier:

$\mathrm{T} 1$

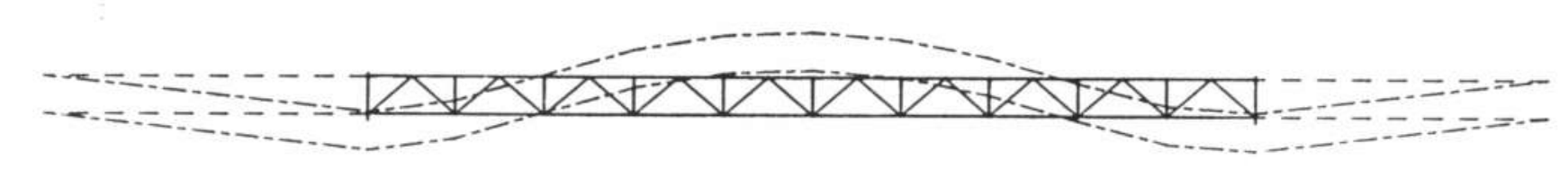

Mode 11 ( 0 node To):

Frequency $3.375 \mathrm{~Hz}$ identifier:

To1

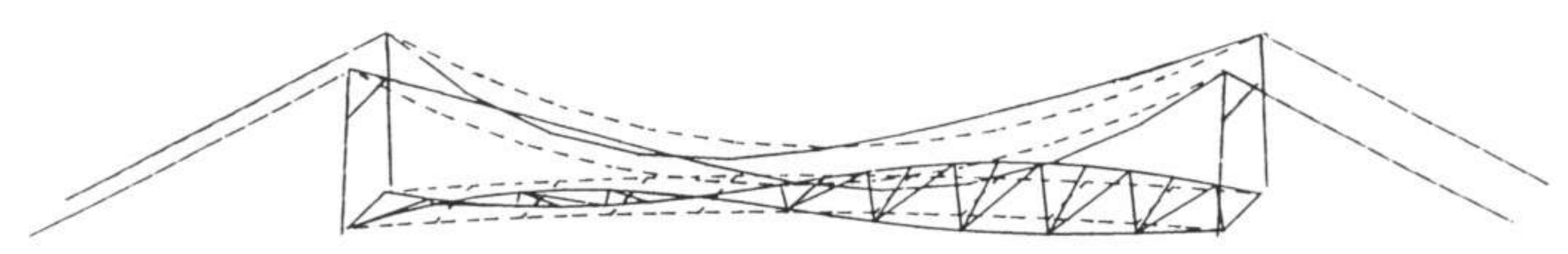

-1 10

Mode 13 (1 node $\mathrm{T}$ asym):

Frequency $3.856 \mathrm{~Hz} \quad$ identifier:

$\mathrm{T} 2$

Fig. 4 (page 2 of 2) Theoretical modes 

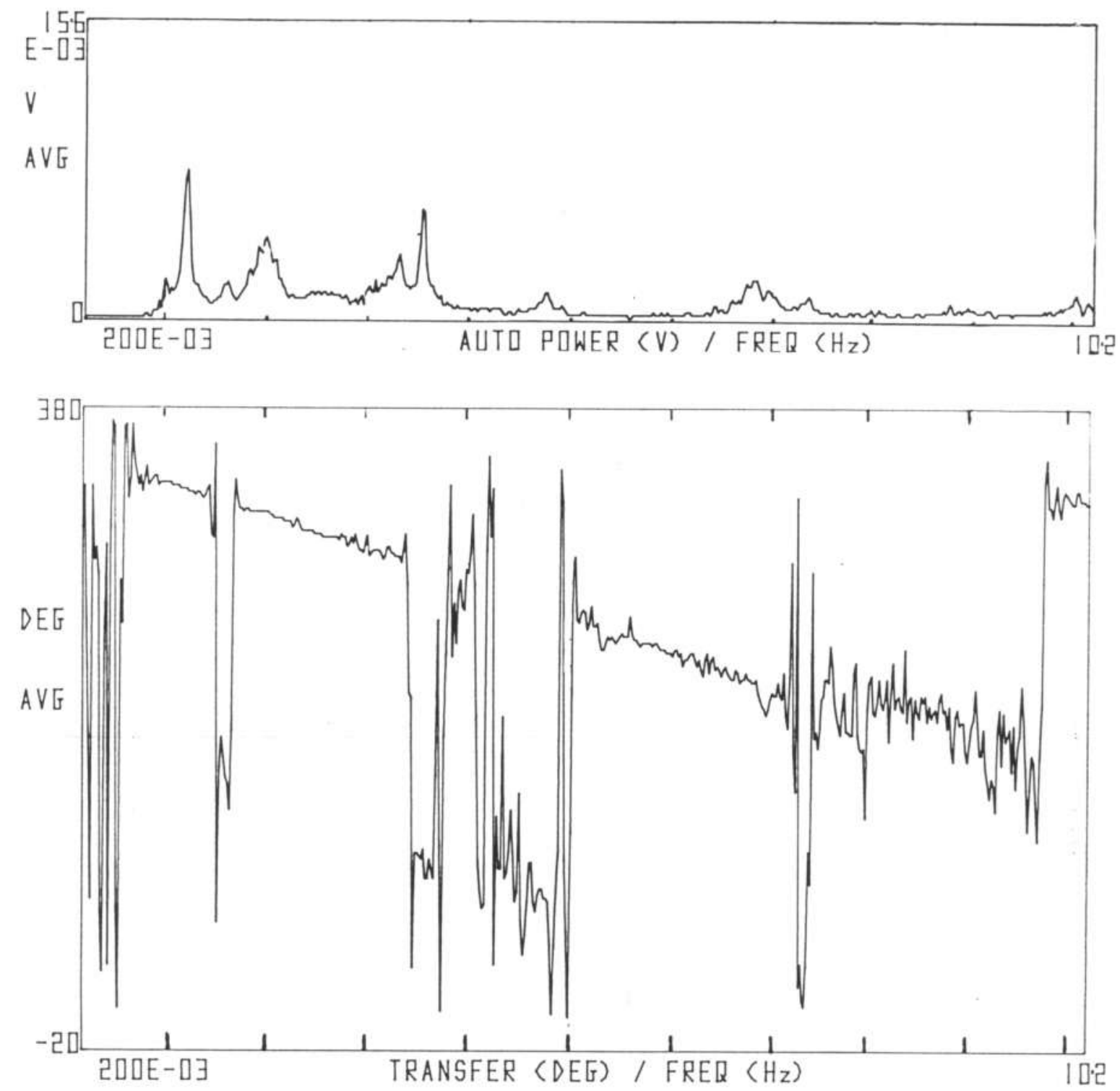

Fig. 5 Spectral analysis of vertical ambient response:

a) Acceleration auto power spectrum for ACB (at $1 \mathrm{~g}$ )

b) Phase angle between accelerometer ACA (at 2g) and ACB (at 1g) 


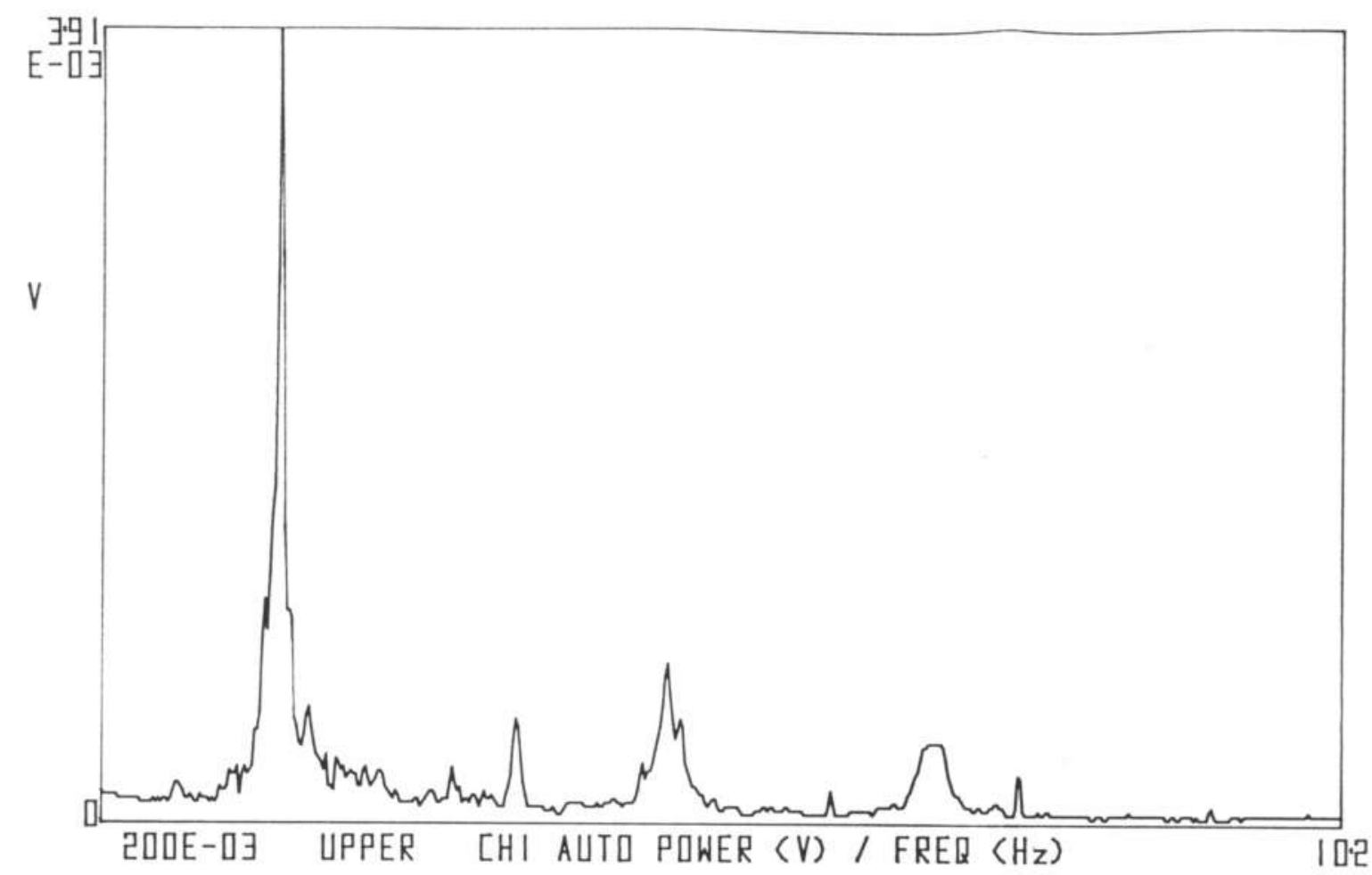

Fig. 6 Spectral analysis of lateral ambient response

Acceleration auto power spectrum for ACB (at 2d) 


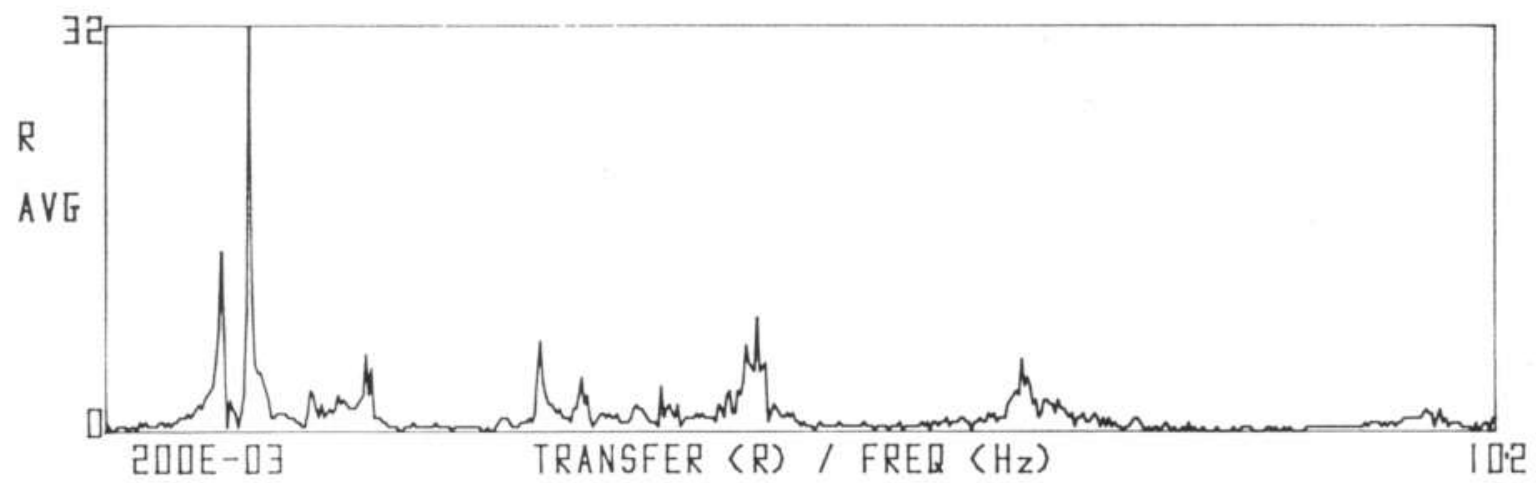

Fig. 7 Spectral analysis of vertical transient response:

Transfer function (ratio) between acceleration responses (for ACA at $2 \mathrm{~h}$ ) and hammer input (at 2h). Scale is arbitrary. 

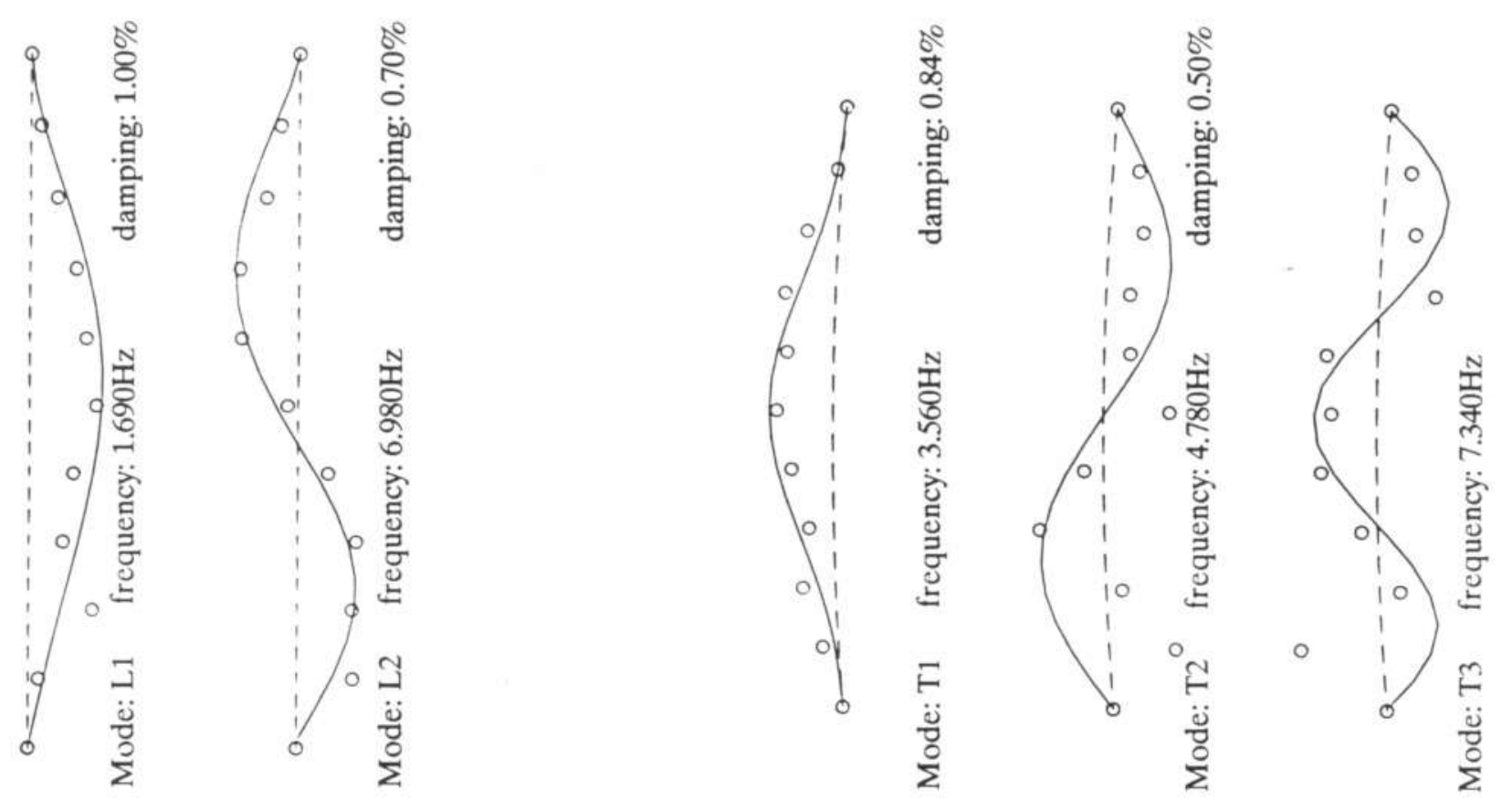

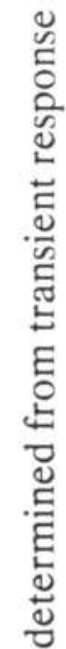

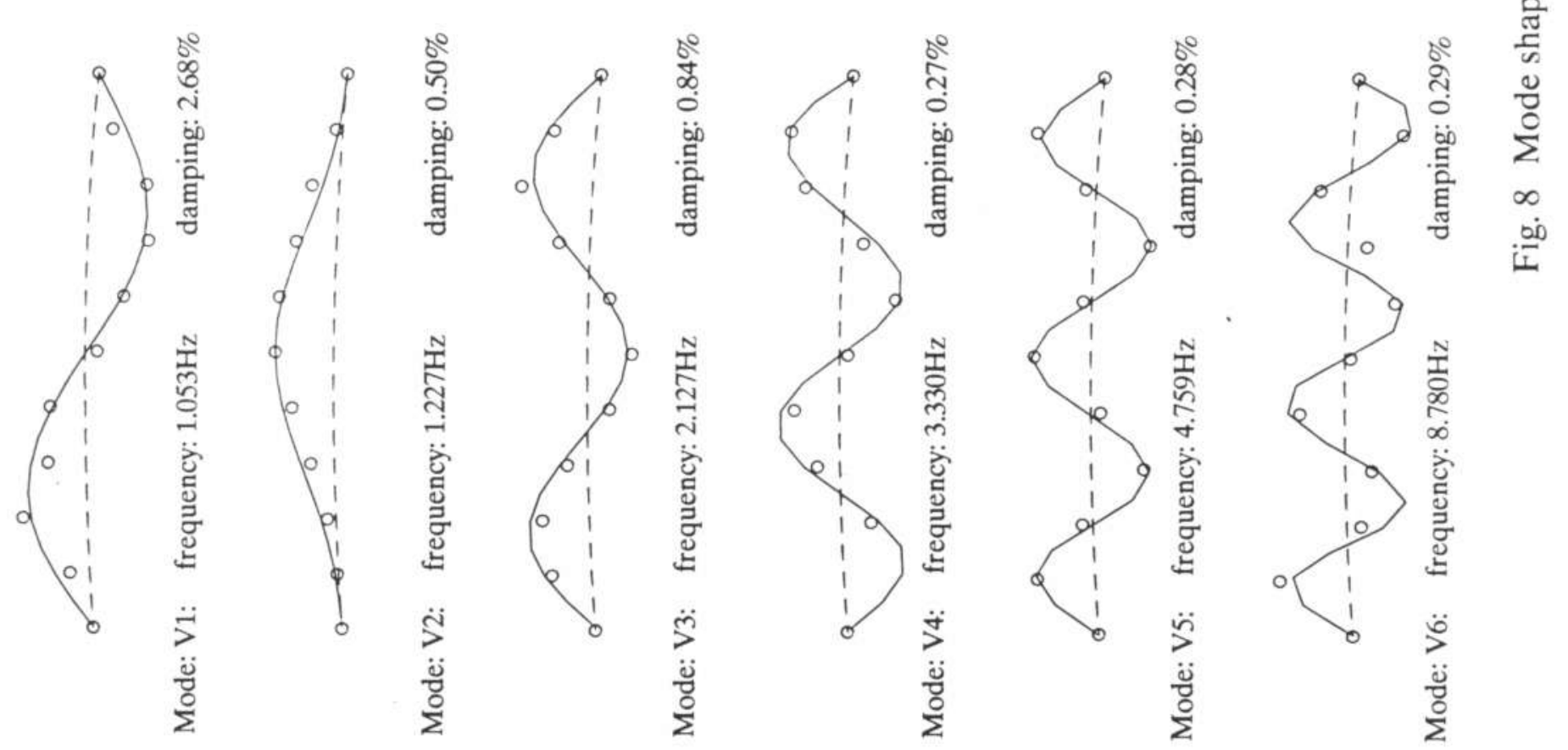

